\title{
O novo negro na América do Sul: representações sobre a fraternidade racial brasileira no jornal afro-americano Chicago Defender (1916-1940)
}

\section{The New Negro in South America: representations on Brazilian racial fraternity in the African-American newspaper Chicago Defender (1916-1940)}

Flávio Thales Ribeiro Francisco ${ }^{1}$

\begin{abstract}
Resumo Este artigo tem como objetivo demonstrar a construção de representações sobre uma fraternidade racial brasileira no jornal afro-americano Chicago Defender no período entre 1916 e 1940. O seu editor, Robert Abbott, foi uma figura importante do ativismo negro na primeira metade do século XX e lutou pela igualdade de direitos entre negros e brancos nos Estados Unidos. Em 1923, com o intuito de testemunhar um outro padrão de relações raciais, Robert Abbott fez uma jornada pela América Latina para demonstrar aos seus leitores que existiam alternativas à ordem social racista norte-americana. Em seu relato de viagem, o jornalista julgou ter identificado na América do sul fraternidades raciais, principalmente no Brasil, que possibilitariam a ascensão de um novo negro no pós-abolição.
\end{abstract}

Palavras-chave raça; Estados Unidos; Brasil; imprensa negra; transnacional.

\begin{abstract}
This article aims to demonstrate the creation of representations of a Brazilian racial fraternity in the African-American newspaper Chicago Defender in the years between 1916 and 1940. Robert Abbott, its founder and editor, was a prominent activist of the black movement in the first half of Twentieth century and struggled for equal rights in the United States. In 1923, with the purpose of witnessing another pattern of race relations, Robert Abbott engaged in a journey to Latin America in order to show to his readers that there were alternatives to the American racist social order. In his travel narrative, the African-American journalist claimed he found racial fraternities in South America, mainly in Brazil, that opened a path to the rise of a New Negro in the pos-abolition.
\end{abstract}

Keywords Race; United States; Brazil; Black Press; Transnational.

Artigo recebido em: 17/07/2015

Artigo aprovado para publicação em: 05/12/2015

\footnotetext{
${ }^{1}$ Doutor pelo Programa de Pós-Graduação em História Social da Universidade de São Paulo. Financiamento: Fundação de Amparo à Pesquisa de São Paulo. E-mail: ffrancisco@usp.br.
}

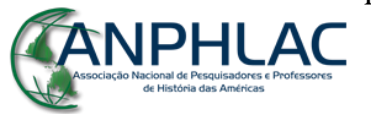

Revista Eletrônica da ANPHLAC, ISSN 1679-1061, N. 19, p. 230-251, jul./dez., 2015.

http://revista.anphlac.org.br 
As representações do Brasil como uma democracia racial não foram construídas somente a partir das visões das elites brasileiras, supostamente interessadas em desmobilizar os ímpetos de um ativismo negro no Brasil. A ideia de uma harmonia racial foi explorada e compartilhada por diferentes segmentos da sociedade, até mesmo por lideranças negras brasileiras preocupadas em confrontar os projetos de uma nação branca e afirmar incorporação simbólica da população negra à identidade nacional (FRANCISCO, 2013).

Além dos brasileiros, estrangeiros também difundiram essas representações, fazendo, principalmente, o exercício de comparação entre a sociedade brasileira e a norteamericana. Dentre eles, podemos citar ativistas afro-americanos como William Dubois, que considerou existir no Brasil uma ordem social livre de práticas racistas, que possibilitaria a ascensão social de pardos e negros (HELLWIG, 1992). Nesse contexto, a imprensa negra dos Estados Unidos teve um papel primordial na difusão de um paraíso racial brasileiro entre os seus leitores, demonstrando que em outras nações havia a possibilidade de uma convivência pacífica entre negros e brancos. O jornal Chicago Defender foi um dos periódicos que mais publicaram textos sobre o Brasil, utilizando o exemplo do país sul-americano de maneira sistemática para confrontar o racismo nos Estados Unidos e para estruturar representações sobre a sociedade brasileira através da noção de um novo negro, que veremos mais adiante.

Este jornal foi a principal publicação da imprensa afro-americana na primeira metade do século XX, cumprindo um papel fundamental na formação de uma esfera pública negra nos Estados Unidos. Para compreendermos a ascensão deste periódico e o seu posterior interesse nas relações raciais brasileiras, é importante tratarmos das origens de seu fundador e editor, Robert Abbott, que tem a sua trajetória política e profissional confundida com a do Chicago Defender. A política editorial do jornal seguiu o viés integracionista de Abbott em um espectro político variado do ativismo afro-americano que emergiu na primeira década do século XX. Abordar a história do Chicago Defender e de Robert Abbott é acompanhar o processo de institucionalização das organizações negras em um período anterior ao do Movimento pelos Direitos Civis da década de 1950.

Robert Abbott nasceu em 1868, no estado da Geórgia, filho de libertos alfabetizados que fariam a transição para a liberdade de maneira menos turbulenta que a maioria da população negra. Educado no interior de uma classe de negros com uma situação estável no sul do país, Abbott teve uma formação que lhe possibilitou o acesso a uma rede de instituições educacionais

\section{GANPHLAC}

Revista Eletrônica da ANPHLAC, ISSN 1679-1061, N. 19, p. 230-251, jul./dez., 2015. http://revista.anphlac.org.br 
criadas com o intuito de promover e garantir a cidadania negra nos Estados Unidos (OTTLEY, 1955). Em 1896, Abbott, após experiências breves como tipógrafo, deixou o sul do país e rumou ao norte para estudar Direito na Kent Law School, na cidade de Chicago. Com diploma em mãos, no entanto, não conseguiu se firmar como advogado, encontrando dificuldade para formar uma clientela, pois havia uma certa rejeição à sua pele excessivamente escura. Robert Abbott foi aconselhado por um colega a mudar de área, pois não tinha o "perfil de um profissional respeitável”.

Em 1905, após algumas frustrações, Robert Abbott investiu seus parcos recursos em um jornal voltado para a população negra de Chicago. O Chicago Defender circulou pela primeira vez com uma edição de quatro páginas e uma tiragem de 300 exemplares. Como não tinha condições de manter um escritório para editar o periódico, Abbott utilizou o próprio dormitório, um pequeno quarto alugado na casa de uma família negra. A fase de precariedade do Chicago Defender durou cerca de cinco anos, o próprio jornalista duvidou da possibilidade do periódico prosperar, sentindo-se tentado por propostas para lecionar em seu estado natal.

Em 1910, Abbott apostou no talento de John Smiley, jornalista que foi fundamental para a transformação do Defender - uma pequena folha que circulava pelas esquinas de Chicago -, em um jornal de influência nacional, atingindo as populações negras em todo o território norte-americano. Uma das principais estratégias de Smiley foi a de transformação do layout do Chicago Defender, seguindo a referência dos grandes jornais do período. O periódico, com mais imagens e tipos maiores, explorou de maneira sensacionalista a violência racial no sul dos Estados Unidos, mas também reforçou uma política editorial de denúncia do racismo e de luta pela igualdade de direitos.

O sucesso do Chicago Defender, entretanto, somente foi possível devido ao aumento da população negra de Chicago. Na década de 1910, o fluxo de migrantes negros do sul do país para as grandes cidades do norte se intensificou, criando e aumentando o tamanho de comunidades negras em cidades como Chicago, Nova Iorque, Boston e Detroit. Esse fenômeno ficou conhecido como Grande Migração, ou seja, um deslocamento em massa de trabalhadores negros que fugiam da violência racial e de uma economia em recessão (GROSSMAN, 1989). Na cidade de Chicago, a população negra triplicou, atingindo o número de 80 mil habitantes em 1920. Sendo assim, a migração ampliou o número de leitores do periódico, possibilitando a sua profissionalização.

\section{GANPHLAC}

Revista Eletrônica da ANPHLAC, ISSN 1679-1061, N. 19, p. 230-251, jul./dez., 2015. 
Robert Abbott, compreendendo a importância do fenômeno, criou uma espécie de campanha para que os negros deixassem o sul e se mudassem para as cidades do norte, onde se consolidavam os polos industriais. Em 1915, o jornal já circulava também entre as comunidades negras do sul, em uma operação de distribuição que envolveu os funcionários de trem da companhia Pullman, que tinha uma grande quantidade de negros. Eles divulgavam e distribuíam o jornal assim que chegavam às cidades do sul. O Chicago Defender não encontrou dificuldades para atrair a atenção de leitores na região, já que os jornais negros dos estados sulistas recorrentemente tinham as suas redações empasteladas por hordas racistas que tinham o intuito de silenciá-los.

Se, por um lado, o Chicago Defender se consolidou como o grande jornal da imprensa afro-americana por conta da Grande Migração, por outro, o periódico se transformou em um agente fundamental de promoção do deslocamento de trabalhadores negros. Em 1914, a Primeira Guerra Mundial interrompeu o fluxo de imigrantes europeus, abrindo espaço para as mulheres e os negros nas indústrias. Essa tendência se reforçaria em 1917, com o recrutamento de soldados para o exército dos Estados Unidos, que entrariam para o conflito na Europa posteriormente (Ibidem, 1989). O jornal de Robert Abbott se apresentou como um guia, informando sobre oportunidades de emprego nas cidades do norte e alertando os leitores sobre esquemas enganosos de falsos agentes. Os leitores do sul, reconhecendo o papel desempenhado pelo Chicago Defender, enviavam cartas para o editor pedindo empregos e, até mesmo, dinheiro para fazer a viagem para Chicago (SCOTT, 1919).

A campanha em prol da migração se revelou, sobretudo, na construção de uma representação negativa dos estados do sul dos Estados Unidos. Nas páginas do Chicago Defender, notícias e artigos sobre linchamentos e outras modalidades de violência racial ajudavam a compor um retrato dramático, demonstrando a impossibilidade de uma mobilidade social negra naquela região. Os estados do sul, portanto, na perspectiva do periódico, ainda sofriam com o legado da escravidão, aparecendo como espaços do atraso em relação às cidades do norte que se transformavam em grandes centros industriais. A migração se apresentava como a única saída para os negros do sul:

O Chicago Defender convida todos para vir para o Norte, onde há bastante espaço para os homens bons, sóbrios e trabalhadores. Aqui há bastante trabalho. Para aqueles que não irão trabalhar, as cadeias cuidarão de você. Quando você tiver os seus 90 dias

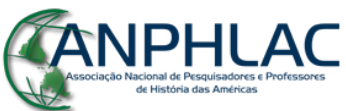

Revista Eletrônica da ANPHLAC, ISSN 1679-1061, N. 19, p. 230-251, jul./dez., 2015. 
de trabalho duro, você terá aprendido como trabalhar. Em qualquer lugar do país a vida é melhor do que no Sul [...] Não deixe os malucos te enganarem, venha se juntar ao grupo dos livres. Deixe a opressão para trás. Quando você atravessar o Rio Ohio, respire o ar fresco e questione-se: "Por que eu não vim antes?" (CHICAGO DEFENDER, 10 de fevereiro de 1910, p. 13) [Tradução do autor].

O excerto acima traduz a posição política do Chicago Defender, que, além de escancarar as mazelas das populações negras no sul dos Estados Unidos, procurou difundir a ideia de que as cidades do norte eram espaços livres de práticas racistas. Atravessar o Rio Ohio significava a inserção em uma nova relação de trabalho que acompanhava a modernização da sociedade norte-americana. Nesse sentido, o periódico negro empenhou-se em construir a imagem de um negro moderno associado ao processo de industrialização e urbanização dos grandes centros e em contraposição à precariedade da situação dos trabalhadores negros nas cidades do sul do país.

Nas décadas de 1910 e 1920, configurou-se a representação de um novo negro nos discursos do ativismo afro-americano. À medida que as lideranças negras se articulavam para lutar pela integração, reforçavam a necessidade de uma nova postura diante do racismo norte-americano. As expressões desse movimento variavam entre ações políticas - contra a segregação e a discriminação racial - e iniciativas na literatura através de uma linguagem capaz de capturar as mudanças ocorridas com a Grande Migração. A NAACP (National Association for the Advancement of Colored People), fundada em 1909, sob a liderança do intelectual William DuBois, mobilizou-se em torno de ações jurídicas para combater o racismo em instituições públicas e privadas (JONAS, 2005). Já o Harlem Renaissance, um grupo de intelectuais negros articulados na cidade de Nova Iorque, retratou as experiências das classes populares negras neste período de mudanças (BLOOM, 2004).

Para Henry Louis Gates (1998), a ideia de um novo negro começou a circular no século XIX, como uma reação às representações racistas difundidas na literatura e em ilustrações, configurando-se em um conjunto de discursos sobre a dignidade negra em uma sociedade estruturada por hierarquias raciais. O Chicago Defender fazia parte desse universo e, ao seu modo, criou as suas próprias representações sobre a população negra na modernidade norte-americana. Através de reportagens, editoriais e, até mesmo, publicidade, o jornal de Robert Abbott transformou Chicago, Nova Iorque e outros grandes centros urbanos em refúgios da violência racial e espaços privilegiados para a ascensão de um novo negro nos Estados

\section{GANPHLAC}

Revista Eletrônica da ANPHLAC, ISSN 1679-1061, No. 19, p. 230-251, jul./dez., 2015. 
Unidos. Em 1919, por exemplo, o periódico publicou em suas páginas a propaganda de um projeto imobiliário em Nova Iorque, na qual se associava investimento financeiro e igualdade de direitos:

\begin{abstract}
CHAMADO para pessoas empreendedoras e com respeito próprio: vivam, sejam proprietários e invistam. Vivam em lugares onde prevaleçam direitos iguais e oportunidades. Tenham seu próprio lar, sejam independentes... Invistam em terrenos valiosos e desejados e o seu dinheiro vai render. Um grande boom em terras está próximo, de fato isso já acontece aqui agora. Lucram-se centenas e milhares de dólares em imóveis em Nova Iorque e em áreas adjacentes. (CHICAGO DEFENDER, 12 de abril de 1919, p. 4) [Tradução do autor].
\end{abstract}

No entanto, foi a cidade de Chicago, base de operação do jornal, e um dos principais centros de recepção dos migrantes sulistas, o principal alvo do projeto político do Defender que, além de promover a migração, insistia na divulgação da cidade como um centro econômico dinâmico capaz de incluir socialmente os trabalhadores que se deslocavam pelo território norteamericano. Nas páginas do periódico negro, além de ofertas de emprego na indústria, Chicago também oferecia entretenimento que poderia ser desfrutado pela população negra, sem as limitações de políticas segregacionistas. Na seção dedicada a eventos, os leitores poderiam se informar sobre concertos musicais, filmes em cartaz e noites dançantes que revelavam o fervor cultural na cidade. As modalidades esportivas também se transformaram em grandes atrações, com coberturas de luta de boxes e do cotidiano dos Chicago Giants, equipe de baseball com atletas negros.

O Chicago Defender criou um quadro de prosperidade negra, flertando com narrativas do Sonho Americano que, embora estivesse associado à sociedade norte-americana dos anos 50, já se configurava nesse período em torno de valores como o trabalho duro, a aquisição de riquezas e também o consumo (DESANTIS, 1993). No periódico, os poucos exemplos de self-made man tornaram-se símbolos da mobilidade social proporcionada pelas "metrópoles negras". Madam C. Walker, milionária do mercado de cosméticos, foi uma das principais figuras exploradas pelo Defender que recorrentemente publicava a história de vida de uma pobre mãe solteira que se enriqueceu com a invenção de uma fórmula de creme para alisar os cabelos das mulheres negras. O jornal também promoveu a imagem de seu fundador, demonstrando a autodeterminação de Robert Abbott para construir o seu patrimônio.

\title{
CANPHLAC
}

Revista Eletrônica da ANPHLAC, ISSN 1679-1061, No. 19, p. 230-251, jul./dez., 2015. http://revista.anphlac.org.br 
Todo o esforço de difusão das ordens sociais inclusivas no norte dos Estados Unidos não teria grande resultado se o direito ao voto não fosse garantido à população negra. Durante a Reconstrução (1865-1877), logo após a abolição e a Guerra Civil, esforços foram feitos para que os negros pudessem acessar as urnas como eleitores, reforçando o processo de transformação dos libertos em cidadãos. A Décima Quinta Emenda da Constituição norteamericana proibiu qualquer restrição ao voto baseado em critérios raciais, contudo foi incapaz de confrontar a mobilização de supremacistas brancos associados ao Partido Democrata que utilizaram inúmeros artifícios para limitar a participação dos negros (FONER, 1988). Após 1877, as políticas de promoção da cidadania negra foram desmanteladas por forças políticas comprometidas com a segregação racial nos estados do Sul. Em Illinois, estado onde Chicago se situa, leis que proibiam o voto dos negros foram eliminadas após a abolição (REED, 2005).

$O$ Chicago Defender atuou de maneira efetiva nas eleições, principalmente as locais, mobilizando o voto negro. O periódico sempre manifestou o seu apoio ao Partido Republicano, explorando a aura em torno de Abraham Lincoln. Nesse sentido, o jornal de Robert Abbott cumpriu um papel importante na articulação de redes clientelistas de negros e algumas comunidades de imigrantes que estavam associadas à máquina eleitoral republicana (GUGLIEMO, 2004). Os eleitores negros, por exemplo, foram decisivos nas vitórias de William Thompson, que governou Chicago quatro vezes entre 1915 e 1930. O Defender não perdeu a oportunidade de demonstrar a sua força:

Essa é uma vitória não somente para Thompson, mas para o Chicago Defender também. Esta afirmação é evidenciada por uma manchete com título em negrito na edição de quarta que dizia: "NEGROS VOTEM EM BIG BILL", enquanto todos os outros jornais dolorosamente admitem que foi o voto de nosso grupo de pessoas que aniquilou as forças combinadas da oposição. A modéstia nos impede de alegar que "o Maior Semanário do Mundo" tem mais influência política do que todos outros jornais diários combinados, mas sãos os resultados que contam. (CHICAGO DEFENDER, 5 de Abril de 1919, p. 1) [Tradução do autor].

As representações das metrópoles negras retratadas no Chicago Defender, contudo, seriam desafiadas pela realidade das relações raciais na sociedade norte-americana. Apesar da demanda por trabalhadores nas indústrias do norte, que atraíram milhares de migrantes, e as pequenas aberturas que possibilitavam a mobilidade social de alguns profissionais negros, as hierarquias raciais se estabeleceram em todo o território, não se restringindo aos "infernos

\section{GANPHLAC}

Revista Eletrônica da ANPHLAC, ISSN 1679-1061, N. 19, p. 230-251, jul./dez., 2015. http://revista.anphlac.org.br 
raciais" do sul do país. Em 1919, várias cidades do país se transformaram em palcos de confrontos entre negros e brancos. Historiadores que se debruçaram sobre os eventos violentos do "Verão Sangrento" destacaram o crescimento das comunidades negras e a expectativa de inclusão social com a participação de regimentos negros na Primeira Guerra Mundial como causas dos conflitos. Soldados negros, ao retornarem aos Estados Unidos, exigiam o fim da discriminação racial nas instituições e os soldados brancos reivindicavam os seus postos em vários setores da indústria, parte deles ocupados por negros (ABU-LUGHOD, 2007).

Chicago, para desespero de Robert Abbott, sofreu com o confronto mais violento de todos, que durou treze dias. No Lago Michigan, recorrentemente retratado como uma área de lazer pelo Chicago Defender, uma briga entre banhistas iniciou-se após o afogamento de um garoto negro alvejado por uma pedra. A polícia se negou a prender um cidadão branco suspeito do crime, provocando uma reação violenta por parte da população negra. O prefeito de Chicago, sem contar com uma força de repressão organizada para contornar a situação, lançou mão de uma milícia. O saldo do tumulto foi de 38 mortos, sendo 23 deles negros e 15 brancos.

Após o conflito, Robert Abbott, através de seu periódico, lamentou a violência do confronto e procurou entender as suas causas. Nos vários artigos publicados no editorial do jornal, o editor reforçou a tese de que os negros que haviam lutado na Primeira Guerra Mundial não aceitariam mais as diversas práticas racistas da sociedade norte-americana, o que acabou ocasionando enfrentamentos em algumas cidades do norte. Abbott também reconheceu que o racismo não era um fenômeno circunscrito aos estados do sul, manifestava-se também nas cidades retratadas como refúgios da violência racial. Entretanto, para ele, as práticas racistas não haviam se originado das relações sociais do norte, foram difundidas por migrantes brancos do sul habituados a uma outra cultura racial.

Enfim, no Chicago Defender - em textos publicados por Abbott e outros colaboradores -, o tumulto foi considerado como um sintoma das mudanças nas relações raciais norte-americanas. William S. Scarborough, reitor da Wilberforce University, escreveu em um editorial para o jornal sobre a necessidade de a sociedade entender a emergência de um novo negro que exigia uma democracia de fato, livre de práticas que estruturavam uma hierarquia racial:

\section{CANPHLAC}

Revista Eletrônica da ANPHLAC, ISSN 1679-1061, N. 19, p. 230-251, jul./dez., 2015. 
[...] Ele é completamente um novo homem, com novas ideias, novas esperanças, novas aspirações e novos desejos. Ele não se submeterá pacificamente às condições anteriores sem protestar vigorosamente e nós não deveríamos pedir que mantivessem um comportamento moderado. Há um novo negro entre nós, não deveríamos esperar também por um novo homem branco? A guerra tem revolucionado o mundo inteiro, mudando o modo de pensar e de agir. Novas pessoas com novos pensamentos devem assumir o fronte agora. (CHICAGO DEFENDER, 30 de agosto de 1919) [Tradução do autor].

A cidade de Chicago, assim como Nova Iorque, Boston e Detroit, nunca pôde ser considerada um paraíso racial. Desde os seus primórdios, muito antes da Grande Migração, a pequena população de negros já sofria com as barreiras raciais. A segregação racial e os linchamentos não faziam parte do repertório racista da cidade, mas uma hierarquia racial se constituiu e revelou os seus aspectos mais violentos com o crescimento da comunidade negra a partir do fluxo de migrantes negros do sul. O entusiasmo em torno da possibilidade de uma mobilidade social negra ignorou as tensões raciais que explodiram em confrontos pelo território norte-americano.

A representação de um novo negro foi abalada pela realidade das relações raciais. Entretanto, esta representação não desapareceu das páginas do Chicago Defender e foi alimentada por experiências negras em outros países, sobretudo os da América Latina. Nesse período, a sociedade brasileira passou a ser divulgada de maneira frequente nos jornais da imprensa negra, principalmente o periódico de Robert Abbott, que se transformaria em um entusiasta do Brasil. Nesse sentido, o país sul-americano foi incorporado à agenda política do Chicago Defender, que demonstrava claramente a sua posição integracionista.

\section{O Brasil no Chicago Defender}

O Chicago Defender não foi o pioneiro, no universo afro-americano, na difusão do Brasil como uma sociedade livre do racismo. Intelectuais como William DuBois, por exemplo, já mencionavam a capacidade da sociedade brasileira de incorporar a sua população negra sem os problemas de um racismo como o estruturado nos Estados Unidos. Em 1914, ele questionou o posicionamento do ex-presidente Theodore Roosevelt, que publicara suas experiências de viagem ao Brasil na obra Through the Brazilian Wilderness. DuBois refutou a inferioridade dos negros brasileiros afirmada por Roosevelt e elogiou o processo de miscigenação dos brasileiros.

\section{GANPHLAC}

Revista Eletrônica da ANPHLAC, ISSN 1679-1061, No. 19, p. 230-251, jul./dez., 2015.

http://revista.anphlac.org.br 
(HELLWIG, 1992, p. 31-34) No ano seguinte, a revista Crisis, editada pela NAACP, publicou o relato de viagem de R. W. Merguson, que se impressionou com a variedade de tons de pele e as relações pacíficas dos brasileiros, consideradas distintas das dos norte-americanos:

\begin{abstract}
Algumas das pessoas mais refinadas são os negros brasileiros. Eles conhecem bem a situação infame dos Estados Unidos. Eles têm noção sobre os linchamentos, sobre a legislação racista e o cruel desrespeito pela lei e ordem que é tão comum nos Estados Unidos. Sobre essas formas de injustiça, um brasileiro naturalmente diria que jamais elas aconteceriam no Brasil. Nunca no Brasil o preconceito norte-americano, o ódio e uma doutrina de inferioridade seriam implantados. (CRISIS, novembro de 1915, p. 38-43) [Tradução do autor].
\end{abstract}

Antes do Verão Sangrento de 1919, o Chicago Defender publicou algumas notícias sobre o Brasil, mas elas ainda não estavam alinhadas à agenda política do jornal. Em 1916, Robert Abbott revelou o seu interesse pelo país ao contratar Patti Brown, cantora soprano que fazia um tour pela América do Sul, como correspondente do Defender. Ele já partilhava da noção do Brasil como paraíso racial e utilizou os serviços de Brown para confirmá-la. Em sua passagem pelas cidades de Salvador e Rio de Janeiro, como se tornaria comum nos relatos de afro-americanos, Patti Brown chamou a atenção do leitor do Chicago Defender para a "mistura racial" dos brasileiros, mas também destacou a presença dos negros em ocupações que a população negra não tinha acesso nos Estados Unidos:

\footnotetext{
Eu visitei muitos prédios públicos e percebi que os negros predominavam nesses espaços. No correio, um edifício que havia sido construído por um empreiteiro negro, o encarregado tinha a pele morena. Além daqueles em treinamento, os atendentes e os carteiros eram mestiços. Nos bancos, nas casas de comércio, nas lojas e nas mecânicas, negros, brancos, homens e mulheres de aparência inteligente falam português e espanhol... Os policiais, os bombeiros, os condutores de bondes são de todas as cores. Os mais prósperos médicos, advogados, jornalistas e pensadores têm a pele escura. Eu tive um encontro com o Arcebispo do Amazonas que tem autoridade sobre brancos e negros em sua paróquia, ele era um homem negro. (CHICAGO DEFENDER, 1 de abril de 1916, p. 6) [Tradução do autor].
}

A partir dos relatos "pioneiros" de Patti Brown e de outros colaboradores do jornal, o Brasil foi se estabelecendo como modelo de sociedade na qual os negros poderiam ascender socialmente sem as barreiras raciais presentes na sociedade norte-americana. No princípio, o país foi retratado como um paraíso distante, porém, à medida que as tensões raciais passaram a se manifestar de maneira escancarada nas cidades do norte, Robert Abbott foi demonstrando

\title{
GANPHLAC
}

Revista Eletrônica da ANPHLAC, ISSN 1679-1061, N. 19, p. 230-251, jul./dez., 2015. http://revista.anphlac.org.br 
cada vez mais interesse pela experiência dos negros brasileiros. O Chicago Defender, então, passou a publicar exemplos de mobilidade social negra, dados da economia brasileira e, até mesmo, oportunidades para pessoas que pretendiam deixar os Estados Unidos e se estabelecer em países sem as práticas racistas comuns aos norte-americanos.

\section{Robert Abbott na América Latina}

Em 1923, quatro anos após o Verão Sangrento, o Chicago Defender continuava a lutar contra as práticas racistas em Chicago e em outras partes do território norte-americano. Com a preocupação de demonstrar os excessos da violência racial nos Estados Unidos, Robert Abbott investiu na sociedade brasileira como um exemplo a ser seguido pelos norte-americanos. O novo negro que ainda não havia encontrado o seu lugar na modernidade norte-americana, poderia emergir no Brasil ou em outras sociedades latino-americanas, consideradas como ordens sociais inclusivas. Abbott, preocupado em compreender um padrão de relações raciais na América Latina, resolveu fazer uma jornada pelo continente, que se iniciou na cidade do Rio de Janeiro e terminou na cidade de Havana.

O jornalista não foi o primeiro afro-americano a fazer uma viagem pela América Latina, mas foi o primeiro a escrever um relato sobre uma jornada pelo continente. A Europa e a África já eram destinos comuns para muitos viajantes negros, que transitavam nas redes transatlânticas do abolicionismo britânico ou circulavam no continente africano identificando terras para o assentamento de afro-americanos desiludidos com o destino nos Estados Unidos. Portanto, Robert Abbott fez parte de uma tradição de viajantes negros que, segundo Virginia Smith (2009), criaram narrativas de deslocamento que revelaram a procura de uma identidade negra distinta da construída a partir de imagens de imoralidade e inferioridade na sociedade norte-americana. Uma viagem para o Brasil, nesse sentido, poderia significar a fuga, ainda que temporária, da violência racial dos Estados Unidos.

Os relatos escritos por Abbott foram publicados em uma série de dez artigos no Chicago Defender, ainda no ano de 1923. O roteiro do jornalista contou com passagem pelo Brasil, Argentina, Uruguai, Chile, Peru, Panamá e Cuba. A sua narrativa foi estruturada em dois eixos: a mobilidade social negra e a ameaça do racismo norte-americano a um padrão pacífico de relações raciais. Por um lado, Robert Abbott procurou demonstrar aos leitores a situação dos

\section{GANPHLAC}

Revista Eletrônica da ANPHLAC, ISSN 1679-1061, N. 19, p. 230-251, jul./dez., 2015. 
negros, destacando a importância nas economias, a participação na política, as relações sociais no cotidiano e o processo de ascensão. Por outro, retratou a influência negativa de cidadãos norte-americanos que transgrediam culturas marcadas pela harmonia racial com uma etiqueta racista. Nas cidades onde as populações negras tinham forte presença, como no Rio de Janeiro, Abbott direcionou o seu olhar para exemplos positivos de negros que ocupavam posições de destaque; onde os traços das populações negras não estavam presentes, como no Chile, destacou as minorias indígenas e os valores democráticos que permitiam um negro circular por diferentes espaços sem ser importunado por cidadãos racistas.

Nos relatos sobre o Brasil, Robert Abbott organizou a sua narrativa a partir desses dois eixos, pintando um quadro idílico da sociedade brasileira e identificando atos racistas de norte-americanos presentes no Rio Janeiro e São Paulo. Assim que desembarcou em terras brasileiras e iniciou os procedimentos para se hospedar em um hotel, o jornalista e sua esposa foram surpreendidos por compatriotas que impediram a permanência do casal. A única saída foi se instalar em um outro recinto onde o jornalista pudesse, enfim, entrar em contato com o padrão brasileiro de relações sociais, imaginado como livre de qualquer tipo de preconceito racial.

\footnotetext{
Nós chegamos no Glória Hotel. Mas observem! Mesmo aqui nós nos deparamos com o pesadelo do diabólico monstro que, como uma lendária serpente do mar, tem perseguido nossos rastros até o Atlântico Sul, pretendendo fixar residência no Brasil. É o preconceito de cor norte-americano. Até mesmo na justa terra do Brasil, onde os corações pulsam, e cada fibra vibra com as tradições democráticas da Revolução Francesa, a repugnante fobia à cor norte-americana procura se afirmar. Nós fomos avisados cortesmente que não havia vagas, mas sabíamos que não era essa a situação. Após abandonarmos o Hotel Glória, nós fomos para o Hotel Victoria, um estabelecimento brasileiro de primeira classe, onde as acomodações nos foram oferecidas graciosamente e sem hesitação. (CHICAGO DEFENDER, 11 de agosto de 1923, p. 13) [Tradução do autor].
}

Robert Abbott passaria por uma experiência semelhante na cidade de São Paulo, mas os casos de discriminação racial, influenciados sempre por norte-americanos, tiveram um lugar secundário na narrativa. $\mathrm{O}$ jornalista deu grande destaque aos profissionais negros que, segundo a sua visão, eram referências do processo de mobilidade social no período pósabolição. Ao mencionar os exemplos de ascensão social negra, entretanto, iniciou a sua lista com um negro norte-americano. Alfredo Clandenen foi apresentado como um profissional que teve poucas chances no seu país de origem e prosperou no Brasil. Em 1923, ele já era um senhor

\section{GANPHLAC}

Revista Eletrônica da ANPHLAC, ISSN 1679-1061, No. 19, p. 230-251, jul./dez., 2015. http://revista.anphlac.org.br 
de setenta anos com a incrível experiência de ter sido o dentista do Imperador D. Pedro II, quando este ainda ocupava o trono. Para Robert Abbott era importante mostrar aos seus leitores que sofriam no cotidiano com as práticas discriminatórias a trajetória de um afro-americano que progrediu socialmente em uma sociedade inclusiva e prestou serviços a um chefe de Estado.

Alfredo Clandenen, que posteriormente passaria a colaborar com o Chicago Defender, parece ter sido o guia de Abbott no Rio Janeiro. O norte-americano radicado no Brasil facilitou o trânsito do jornalista pela cidade e a sua circulação entre negros "notáveis" da sociedade brasileira. Dentre as referências de ascensão social negra, Abbott citou José do Patrocínio Jr., filho da grande figura do abolicionismo brasileiro e funcionário da embaixada brasileira na Bélgica; Evaristo de Moraes, criminologista, advogado e grande orador; Olympio de Castro, um padre de "grande conhecimento"; Juliano Moreira, médico formado na Escola de Medicina da Bahia que representou o Brasil em um Congresso Internacional de neurologistas em Berlim; Tito Carlos, apresentado como jornalista e escritor com um futuro promissor na área da medicina; Capitão Ignácio Villarinho, oficial do exército brasileiro; e Eloy de Souza e Sampaio Correia, senadores da República. Para Abbott, todas essas figuras representavam o caráter inclusivo da sociedade brasileira, ainda que eles fossem, de fato, uma exceção em meio a uma maioria negra que se encontrava marginalizada. O jornalista identificou uma espécie de sentimento antirracista entre os brasileiros:

\footnotetext{
Não havia problema de raça no Brasil, mas sim um amor pela liberdade que estava encravado profundamente na alma brasileira, existia por parte de muitos líderes brasileiros um esforço imensurável para compreender o sofrimento de todas as classes de humanidade oprimida. (CHICAGO DEFENDER, 11 de agosto de 1923, p. 13) [Tradução do autor].
}

Em São Paulo, Robert Abbott não obteve tanto sucesso para encontrar os negros ascendentes. Ele fez menção somente a T. D. de Castro, apresentado como Ministro do Interior do Estado de São Paulo. No entanto, o seu relato trouxe uma informação que deve ter chamado a atenção de muitos leitores do Chicago Defender. O ministro revelou a sua admiração pelo líder afro-americano Booker T. Washington, figura histórica do movimento negro nos Estados Unidos, o que o levou a batizar o filho com o nome do ativista. Booker T. Washington de Castro já era formado em direito e falava inglês fluentemente, o que o aproximava do perfil de profissionais negros retratados no relato de Robert Abbott. Ao tratar das experiências de Castro,

\section{GANPHLAC}

Revista Eletrônica da ANPHLAC, ISSN 1679-1061, N. 19, p. 230-251, jul./dez., 2015. 
o jornalista afro-americano organizou sua narrativa entre os eixos da mobilidade social negra e da ameaça racista norte-americana. $\mathrm{O}$ filho do ministro era um homem negro que circulava nos espaços da elite paulista, mas enfrentou o racismo na faculdade de Direito. Abbott, no entanto, não identificou um padrão de racismo brasileiro, alegou que os colegas que discriminavam Castro haviam morado nos Estados Unidos e assimilado as práticas racistas dos norteamericanos:

\begin{abstract}
Parece que os estudantes haviam assimilado certo grau de preconceito de cor durante a passagem deles pelos Estados Unidos, tentando colocá-lo em prática com uma cruel oposição ao fato do jovem Senhor de Castro estar na faculdade. Essa experiência é completamente nova em sua vida. Sem se envergonhar, ele imediatamente agiu com as próprias mãos. Ainda que de uma forma natural, ela foi completamente eficaz, direta e duradoura em seus resultados. Senhor Booker de Castro com seus punhos simplesmente "surrou" alguns dos estudantes em uma atitude brasileira sensata, sem ter problemas posteriormente. (CHICAGO DEFENDER, 18 de agosto de 1923, p. 13) [Tradução do autor].
\end{abstract}

Assim como nos casos dos hotéis, a discriminação não tinha raízes nas relações sociais dos brasileiros, era resultado da influência de uma cultura racista norte-americana. Robert Abbott pareceu resistir à ideia de que práticas racistas poderiam fazer parte de uma hierarquia racial estruturada na sociedade brasileira. Em seus relatos de viagem, o jornalista foi, aos poucos, construindo a imagem da América do Sul como um continente que abrigava fraternidades raciais com padrões de sociabilidades completamente diferentes da sociedade norte-americana.

A representação do Brasil enquanto uma ordem social inclusiva não contou somente com o perfil de negros ascendentes, mas também com figuras importantes da história do país. Robert Abbott citou Cruz e Sousa como escritor negro nascido na escravidão e que "recentemente havia ganhado reconhecimento dos brasileiros, sendo homenageado em inúmeros eventos"; Tobias Barreto, filósofo brasileiro, foi citado pelo editor "como um dos maiores negros já produzidos na história do país"; já José do Patrocínio foi comparado ao abolicionista afro-americano Frederick Douglass para dimensionar sua importância para os leitores nos Estados Unidos.

José do Patrocínio, editor do Cidade do Rio, é considerado em todo o Brasil como um dos seus grandes jornalistas. No movimento pela abolição da escravidão, ele teve um importantíssimo papel de protagonista. Ele poderia ser adequadamente apelidado de

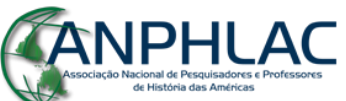

Revista Eletrônica da ANPHLAC, ISSN 1679-1061, N. 19, p. 230-251, jul./dez., 2015.

http://revista.anphlac.org.br 
"Frederick Douglass do Brasil". Através da imprensa e da sua plataforma política lutou em favor do escravo. Ainda hoje uma de suas frases é muito citada: "escravidão é roubo". Uma de suas características mais importantes foi a de nunca aceitar a indicação para cargos públicos. (CHICAGO DEFENDER, 8 de setembro de 1923, p. 13) [Tradução do autor].

O jornalista afro-americano também pintou um quadro amplo da sociedade brasileira, não se restringindo às figuras dos negros ascendentes. Abbott utilizou o termo melting pot para descrever a suposta relação fraterna entre negros e brancos no Brasil. Nos Estados Unidos, o termo foi empregado frequentemente para fazer referência ao processo de assimilação dos imigrantes europeus nas primeiras décadas do século XX, que não contemplou outras minorias como negros e asiáticos (GERSTLE, 2001). Nesse sentido, para o jornalista, a sociedade brasileira representava o verdadeiro melting pot, pois havia sido constituída a partir da congregação de todas as "raças". A mistura racial foi considerada o elemento estruturador das relações sociais do Brasil, contrastando com uma outra sociedade marcada por enfrentamentos entre brancos e negros.

Em um cenário auspicioso, sem barreiras para a ascensão social dos negros, as oportunidades econômicas poderiam atrair muitos leitores do jornal. Robert Abbott, que construiu a sua imagem de self-made man com o sucesso do Chicago Defender, concluiu que a economia brasileira tinha um potencial enorme, principalmente na agricultura. $\mathrm{O}$ algodão, gênero associado à escravidão nos Estados Unidos, poderia ser cultivado no Brasil por um grupo de colonizadores afro-americanos. Se na história da nação norte-americana os negros haviam participado da "civilização do algodão" enquanto mão de obra escravizada, no Brasil poderiam protagonizar um esquema lucrativo no Mato Grosso, como indicado por Abbott:

\footnotetext{
O estado do Mato Grosso vem se destacando na produção de algodão numa escala tremendamente grande. $\mathrm{O}$ governo brasileiro tem recentemente começado a dar um estímulo direto à produção desse gênero, principalmente no Mato Grosso. Há um grande interesse entre os elementos pensantes do país na ocupação do estado pelos negros dos estados do sul de nosso país [...] A área do Mato Grosso é imensa e, acima de tudo, existem as condições ideais para a liberdade social. Para um povo que é oprimido diariamente, que os trabalhadores são miseravelmente explorados e que, ao mesmo tempo, são agricultores competentes, as oportunidades oferecidas no estado, na perspectiva dos brasileiros, são excepcionalmente atrativas. (CHICAGO DEFENDER, 18 de agosto 1923, p. 13) [Tradução do autor].
}

Diferentemente da informação do excerto acima mencionado, não há nenhuma evidência de que o governo brasileiro tivesse um projeto para o assentamento de agricultores

\section{CANPHLAC}

Revista Eletrônica da ANPHLAC, ISSN 1679-1061, No. 19, p. 230-251, jul./dez., 2015. http://revista.anphlac.org.br 
afro-americanos no estado do Mato Grosso, a tendência no período foi a de dificultar qualquer iniciativa de imigração de trabalhadores que não fossem europeus (LESSER, 1991). Abbott, no entanto, ignorando como o racismo influenciava a política brasileira, procurou estimular investidores negros com o potencial econômico da nação sul-americana. Em seu texto, o jornalista foi reforçando a noção do Brasil como uma espécie de fronteira de investimentos, que poderia ser explorada por afro-americanos. A modernidade brasileira, que havia incluído a sua população negra após a abolição, apresentava-se como uma alternativa para um seleto grupo de negros endinheirados que não conseguia viabilizar os seus negócios nos Estados Unidos. Na realidade construída por Abbott, o novo negro - aquele que emerge e é incluído na transição de uma ordem escravocrata para uma ordem capitalista - estava mais próximo da experiência brasileira do que da norte-americana.

A capacidade das nações sul-americanas de incluir populações não brancas foi atribuída não somente ao Brasil, mas também aos outros países visitados por Robert Abbott. O Uruguai e a Argentina, que tinham populações negras diminutas, apesar de um histórico de tráfico negreiro na região do Prata, foram retratados como países com "culturas democráticas"; ou seja, não havia nas duas nações práticas racistas que pudessem comprometer a trajetória de um profissional negro, ainda que uruguaios e argentinos tivessem encaminhado um processo bem sucedido de branqueamento das suas populações. O jornalista, entretanto, preferiu focar o seu relato no desempenho da economia dos dois países, demonstrando como saíram de uma situação de "atraso" e se transformaram em potências econômicas, intensificando a competição de norte-americanos e britânicos por parcerias na região. Os ianques, no entanto, não pareciam desfrutar da simpatia das duas nações:

\footnotetext{
Os povos sul-americanos nutrem geralmente um ressentimento latente e constante contra os norte-americanos, baseado no que eles consideram, erroneamente ou corretamente, ser a tendência dos Estados Unidos de assumir uma influência sobre as duas Américas. De fato, na cabeça dos sul-americanos, a Doutrina Monroe foi concebida como algo fortemente associado à ideia da "América para os norteamericanos". Esse sentimento é muito forte na Argentina. Infelizmente, os produtos norte-americanos são sempre tratados com indiferença, independentemente de sua qualidade e a satisfação que possam proporcionar. (CHICAGO DEFENDER, 22 de setembro de 1923, p. A1) [Tradução do autor].
}

No caso do Chile e do Peru, o jornalista não demonstrou o mesmo entusiasmo, embora tenha observado negros participando de maneira efetiva em várias atividades

\section{GANPHLAC}

Revista Eletrônica da ANPHLAC, ISSN 1679-1061, N. 19, p. 230-251, jul./dez., 2015.

http://revista.anphlac.org.br 
econômicas em Lima. Em sua passagem por terras chilenas, Robert Abbott, além de revelar a sua admiração pela Cordilheira dos Andes, teve uma nova oportunidade para retratar o mau comportamento de cidadãos norte-americanos na América do Sul. Em mais um dos vários casos de discriminação racial, Abbott relatou a ação coordenada de compatriotas que ordenaram a sua expulsão de um hotel. Desta vez, contudo, o jornalista recorreu ao cônsul dos Estados Unidos, que nada fez. A sua permanência foi garantida pela influência de amigos chilenos.

\begin{abstract}
Um tempo depois, ao encontrar alguns amigos chilenos, eu os informei sobre o pedido para que eu deixasse o hotel, causando grande surpresa. Contudo, eu fui aconselhado por eles a voltar e permanecer no mesmo estabelecimento. Se eu e minha esposa fossemos incomodados, eles resolveriam o problema. Essa prática discriminatória está totalmente em desacordo com a vida democrática dos chilenos. (CHICAGO DEFENDER, 29 de setembro de 1923, p. 13) [Tradução do autor].
\end{abstract}

Entre dados econômicos, perfis de profissionais negros e casos de discriminação racial, Robert Abbott foi montando um quadro amplo no qual emergia uma América do Sul livre do racismo. O Brasil - que foi tema em quatro dos dez artigos sobre a viagem de Abbott - foi tratado como a principal referência de uma modernidade latino-americana capaz de incorporar suas populações negras. As tradicionais representações de cidades isoladas em florestas tropicais, no Chicago Defender, foram substituídas pelas descrições de grandes centros urbanos como Rio de Janeiro, São Paulo e Buenos Aires, que capitaneavam economias com um enorme potencial de investimentos. Neste cenário idílico pintado pelo jornalista afroamericano, a etiqueta racista dos cidadãos norte-americanos revelava a noção distorcida de democracia de um país que segregava os negros através de leis regionais e locais.

Os relatos de Robert Abbott para a América do Sul, contudo, ignoraram as práticas racistas dos sul-americanos. Os negros ascendentes, descritos pelo jornalista, faziam parte de um pequeno grupo em meio a uma população marginalizada nas duas cidades brasileiras que fizeram parte do roteiro de viagem. A preocupação de Abbott com a afirmação de um paraíso racial no Brasil e nos outros países sul-americanos inviabilizou a compreensão de um padrão de racismo distinto do que se reproduzia nos Estados Unidos. As fraternidades raciais da América do Sul foram construídas e mobilizadas para fazer um contraste com a violência racial dos norte-americanos.

Porém, nem toda a América Latina foi considerada como espaço livre do racismo. Se a América do Sul foi retratada como refúgio, a América Central e a região do Caribe

\title{
GANPHLAC
}

Revista Eletrônica da ANPHLAC, ISSN 1679-1061, No. 19, p. 230-251, jul./dez., 2015. 
apareceram como vítimas da ameaça norte-americana. No relato de Abbott sobre a última etapa de sua viagem - no Panamá e em Cuba -, os negros ascendentes foram substituídos pelo cotidiano de negros que testemunhavam a estruturação de hierarquias raciais. Eventos relacionados à política externa dos Estados Unidos na região foram decisivos para a mudança na abordagem do jornalista. No caso do Panamá, os norte-americanos, interessados na construção de um canal que ligasse os oceanos Atlântico e Pacífico, tiveram papel decisivo na separação do país do território colombiano (YATES, 2008). O apoio aos panamenhos rendeu aos ianques o controle da zona do canal em 1903. Já em Cuba, os norte-americanos gozavam de privilégios desde o processo de emancipação, que contou com a intervenção dos Estados Unidos. A Emenda Platt, que vigorou entre 1901 e 1933, permitiu que a nação norte-americana interviesse na ilha cubana sempre que seus interesses fossem ameaçados (SCHOULTZ, 1998).

Para fazer o relato da ameaça norte-americana nas relações raciais na América Latina, Robert Abbott recorreu aos diálogos com panamenhos que descreviam as inúmeras práticas de discriminação racial. Em uma viagem de taxi para uma área próxima ao Canal do Panamá, o jornalista ouviu do motorista conselhos para não ser surpreendido por brancos racistas. Alguns espaços na região eram extremamente segregados e provavelmente os hotéis não aceitariam acomodar um negro. A etiqueta racista norte-americana, segundo o relato, permeava todas as esferas sociais, e se manifestava principalmente no mercado de trabalho. Os negros eram majoritariamente mal remunerados, e nos dias de pagamento os brancos se alinhavam na "fila dourada", onde recebiam os cheques com valores maiores, enquanto os negros enfrentavam um tempo muito maior na "fila prateada". No Panamá, portanto, prevaleceu a supremacia branca imposta pelos norte-americanos:

\footnotetext{
Aos negros não são permitidas acomodações de primeira classe em hotéis ou cafés da zona norte-americana. E mais: os negros são proibidos de se divertirem no amplo e bonito Parque Columbus na cidade. A maldosa prática norte-americana da discriminação racial acabou prevalecendo junto com todas suas vergonhosas inconsistências. Com certeza, seria uma desgraça para um norte-americano ser visto acompanhado de uma mulher negra à luz do dia. No entanto, tanto aqui como nos Estados Unidos, eles não demonstram escrúpulos ao invadir comunidades negras depois da noite para satisfazer seus desejos animais. (CHICAGO DEFENDER, 13 de outubro de 1923, p. 13) [Tradução do autor].
}

O relato de Abbott sobre a sua visita a Cuba não seria diferente, o entusiasmo com o cenário de Havana tornou-se secundário frente a sua preocupação com a erosão das relações

\section{GANPHLAC}

Revista Eletrônica da ANPHLAC, ISSN 1679-1061, №. 19, p. 230-251, jul./dez., 2015. 
sociais entre negros e brancos. O jornalista identificou durante a sua passagem por Havana a destruição de um legado espanhol pela tentativa dos norte-americanos de criar uma sociedade dividida racialmente. Segundo Abbott, a presença dos ianques havia contribuído para o progresso da economia cubana, mas junto com o capital norte-americano havia chegado o racismo. "Este fenômeno, apesar de já presente entre os cubanos, ainda não se manifestava de forma tão virulenta como na sociedade norte-americana". Assim, ainda havia esperança para os negros cubanos, que, na opinião de Abbott, desfrutavam de maior liberdade e de oportunidades que os afro-americanos:

\footnotetext{
Não há dúvida de que o preconceito racial em Cuba nunca se expressou com a virulência que o caracteriza nos Estados Unidos, ele está confinado ao elemento castelhano-espanhol que é influenciado pelos norte-americanos desde a criação da República. Há muito capital investido em Cuba e com isso aparece também a afirmação do privilégio racial.

O negro em Cuba desfruta um grau muito maior de liberdade social e oportunidade do que nos Estados Unidos. Em sua educação e perspectiva social, ele é estritamente hispânico. (CHICAGO DEFENDER, 20 de outubro de 1923, p. A1) [Tradução do autor].
}

O relato sobre Cuba é fundamental para a compreensão do modo como o jornalista gestou a narrativa de ameaça do racismo norte-americano em plano internacional. A sociedade cubana, segundo o relato de Abbott, já experimentava mudanças negativas nas relações entre negros e brancos. No argumento do jornalista, o racismo atuava como um componente fundamental do repertório imperialista dos Estados Unidos. A onda racista que tomou o território norte-americano se reproduzia na política internacional do país. Robert Abbott, portanto, fazia um discurso que questionava a pretensão dos Estados Unidos de se colocarem mundialmente como uma referência de nação democrática, desconstruindo a ideia de excepcionalismo norte-americano.

Após a sua jornada pela América Latina, Robert Abbott retornou aos Estados Unidos como um homem que testemunhara a realidade das fraternidades raciais, colocando-se como uma autoridade sobre o Brasil e outros países do continente. Entusiasmado com a sua experiência, o jornalista organizou conferências em Nova Iorque e Chicago, confirmando a existência de ordens sociais inclusivas na América Latina, ainda que Panamá e Cuba estivessem sob a ameaça da supremacia racial norte-americana. A partir da agenda integracionista do Chicago Defender, o Brasil foi utilizado sistematicamente como uma referência de harmonia

\section{GANPHLAC}

Revista Eletrônica da ANPHLAC, ISSN 1679-1061, N. 19, p. 230-251, jul./dez., 2015. http://revista.anphlac.org.br 
racial em contraposição ao racismo nos Estados Unidos. Abbott ignorou diversos aspectos das desigualdades entre negros e brancos no Brasil. O importante era que as nações sul-americanas pudessem ser propagandeadas como modelos de mobilidade social negra para uma luta por igualdade de direitos nos Estados Unidos. A América do Sul foi retratada como o espaço privilegiado para a ascensão do novo negro e se transformou em uma referência importante do imaginário afro-americano sobre a diáspora negra, sempre mais atento à África e à Europa.

\section{Considerações Finais}

Ao longo da década de 1930, com a ascensão da Frente Negra no Brasil (1931), o Chicago Defender passou a publicar algumas iniciativas do ativismo negro e, até mesmo, a utilizá-las como referência para o movimento negro nos Estados Unidos. Contudo, o foco na atuação da Frente Negra comprometeu a construção de representações das fraternidades raciais em terras estrangeiras. Afinal, como afirmar a existência de relações harmônicas em uma sociedade na qual se articulava um movimento político de negros? Com a morte de Robert Abbott, em 1940, o Brasil foi, aos poucos, perdendo espaço nas páginas do periódico de maior circulação entre a população afro-americana. As informações sobre a sociedade brasileira circularam durante o auge da supremacia branca nas décadas de 1920 e 1930. No entanto, o interesse pelas sociedades tratadas como fraternidades raciais foi diminuindo à medida que foram abertas algumas brechas políticas e institucionais que possibilitariam na década de 1950 a ascensão do Movimento pelos Direitos Civis.

O objetivo de Robert Abbott na construção de representações sobre o Brasil e outros países sul-americanos foi o de desafiar o racismo norte-americano com referências alternativas à sociedade norte-americana. $\mathrm{O}$ jornalista, operando em um espaço transnacional, procurou, a partir da noção de um novo negro, retratar uma modernidade brasileira e latino-americana capaz de incluir a sua população negra; ou seja, os leitores do Chicago Defender aprenderam com a experiência brasileira que seria possível a sociedade norte-americana trilhar um outro caminho que não fosse aquele orientado por narrativas de superioridade do homem branco. Havia, nesse sentido, uma solução para aqueles migrantes negros que formaram as comunidades das grandes cidades do norte dos Estados Unidos e interpretavam as suas vivências como um momento de

\section{GANPHLAC}

Revista Eletrônica da ANPHLAC, ISSN 1679-1061, N. 19, p. 230-251, jul./dez., 2015. 
transição de uma ordem social ainda marcada pela escravidão para uma outra aberta àqueles dedicados ao trabalho.

\section{Referências bibliográficas}

ABU-LUGHOD, Janet L. Race, space, and riots in Chicago, New York, and Los Angeles. New York: Oxford University Press, 2007.

BLOOM, Harold (org.). The Harlem Renaissance. Philadelphia: Chelsea House Publishers, 2004.

DESANTIS, Alan Douglas. Selling the American Dream: The Chicago Defender and Great Migration of 1915-1919. Tese de Doutorado, Universidade de Indiana, 1993.

FRANCISCO, Flavio Thales Ribeiro. Fronteiras em definição: identidades negras e imagens dos Estados Unidos e da África no jornal O Clarim da Alvorada (1924-1932). São Paulo: Alameda/FAPESP, 2013.

GERSTLE, Gary. American Crucible: race and nation in the Twentieth Century. New Jersey: Princeton University Press, 2001.

GILROY, Paul. O Atlântico Negro. São Paulo: Editora 34, 2001.

GROSSMAN, James R. Land of Hope: Chicago, Black Southerners, and the Great Migration. University of Chicago Press, 1989.

GUGLIEMO Thomas A. Whites on Arrival: Italians, race, color, and Power in Chicago, 18901945. New York: Oxford University Press, 2004.

HELLWIG, David J. (org.). African-American reflections on Brazil's racial paradise. Philadelphia: Temple University Press, 1992.

JONAS, Gilbert. Freedom's sword: the NAACP and the struggle against racism in America, 1909-1969. New York; London: Routledge, 2005.

LESSER, Jeffrey H. Are African-Americans African or American? Brazilian Immigration Policy in the 1920's. Review of Latin American 4, n. 1-2, 1991, p. 115-137.

OTTLEY, Roi. The Lonely Warrior: The Life and Times of Robert S. Abbott. Chicago: H. Regnery Co, 1955.

REED, Christopher Robert. Black Chicago's First Century, 1833-1900. Columbia; London: University of Missouri Press, 2005.

\section{GANPHLAC}

Revista Eletrônica da ANPHLAC, ISSN 1679-1061, N. 19, p. 230-251, jul./dez., 2015. 
SCHOULTZ, Lars. Beneath the United States: a history of U.S. policy toward Latin America. Cambridge: Harvard University Press, 1998.

SCOTT, Emmett J. Letters of Negro Migrants of 1916-1918. The Journal of Negro History, Volume IV, n. 3, (Julho, 1919), p. 290-340.

SMITH, Virginia Whatley. African American travel literature. In: BENDIXEN, Alfred; HAMERA, Judith (ed.). The Cambridge companion to American travel literature. Cambridge: Cambridge University Press, 2009.

YATES, Lawrence A. The U.S. military intervention in Panama: origins, planning, and crisis management, june 1987- December 1989. Washington D.C.: Center of Military History, 2008.

\section{GANPHLAC}

Revista Eletrônica da ANPHLAC, ISSN 1679-1061, N. 19, p. 230-251, jul./dez., 2015. 